\title{
Simplified methodology to estimate the emissivity for roof covers
}

\author{
Zbigniew Zapałowicz, ${ }^{1, *}$ \\ ${ }^{1}$ Department of Heat Engineering, Faculty of Mechanical Engineering and Mechatronics, West Pomeranian University of Technology, \\ Szczecin, al. Piastów 17, 70-310 Szczecin, Poland
}

\begin{abstract}
In a number of countries, producers of roof covers are not obliged by law to estimate the reflectivity and emissivity of their products and make them generally available. However, information concerning these parameters that characterize the surface of roof cover is relevant for building's heat calculations. Adequate choice of kind and color of the roof surface affects the amount of heat transferred between the interior and the environment. Simplified research methodology has been proposed in the paper. This methodology requires that experimental research is carried out and characteristic temperatures of roof and of the air are determined. It is then possible to estimate the emissivity for roof cover from the model of energy balance.
\end{abstract}

\section{Nomenclature}

$G$ - irradiance, $\mathrm{W} / \mathrm{m}^{2}$

$h-$ convective heat transfer coefficient, $\mathrm{W} /\left(\mathrm{m}^{2} \mathrm{~K}\right)$

$q$ - heat flux, $\mathrm{W} / \mathrm{m}^{2}$

$r$ - reflectivity

$R$ - heat resistance, $\left(\mathrm{m}^{2} \mathrm{~K}\right) / \mathrm{W}$

$t$ - temperature, ${ }^{\circ} \mathrm{C}$

$T$ - absolute temperature, $\mathrm{K}$

$U$ - overall heat transfer coefficient, $\mathrm{W} /\left(\mathrm{m}^{2} \mathrm{~K}\right)$

$w$ - wind velocity, $\mathrm{m} / \mathrm{s}$

\section{Greek symbols}

$\delta \quad$-thickness, $\mathrm{m}$

$\varepsilon$ - emissivity

$\lambda-$ thermal conductivity, $\mathrm{W} /(\mathrm{m} \cdot \mathrm{K})$

$\sigma \quad$ - Stephan-Boltzmann constant, $5.67 \cdot 10^{-8} \mathrm{~W} / \mathrm{m}^{2} \mathrm{~K}^{-4}$

\section{Indexes}

a - absorption

A - ambient

$C$ - roof covering (roofing paper)

$e$ - equivalent

$H$ - sky (horizon)

$r$-irradiance

$R$ - interior

$S-$ sun

SI - styrofoam on the side of roofing paper

SII - styrofoam on the side of interior

$\beta$ - incidence angle of solar beams

$\lambda-$ conductivity

\section{Introduction}

Effective energy consumption is one of fundamental strategic targets of governments in many countries [1]. Decrease of energy consumption causes in each economy that the so far used sources are sufficient and advancement of the energy sector can be less dynamic.

A significant consumer of heat and electricity is the sector of construction [2-5]. One of ways to diminish the heat energy consumption in constructing is adequate choice of applied building materials [6-8]. The issue has been recognized also by producers and scientists of roof covers. Appropriate choice of kind and color of roofing affects meaningfully the energy balance of a building [912]. The amount of energy transferred between the building's interior and its environment can be significantly reduced by application of the right roofing material with right reflectivity and emissivity of roofing outer layers [13-15]. In some countries, producers of roof covers have created organizations to promote the so called "cool roofing" [16]. They publish information concerning a.o. reflectivity and emissivity of outer layers of roof covers.

Unfortunately in too many countries, producers of roof covers are not associated and there are not juridical regulations that would oblige the producers to include reflectivity and emissivity in technical data concerning their products.

The present paper proposes simplified estimate methodology of emissivity for roof covers. The methodology requires, as a matter of fact, experimental research to be carried out, however, its implementation is not difficult. 


\section{Model of heat transfer for roof}

In papers $[17,18]$ the model of heat transfer for roof proposed by author is being presented. It is assumed for the model that the roof is in a quasi-state condition. Fig.1 shows energy fluxes that are transferred among the roof and particular media.

Energy balance equation written for $1 \mathrm{~m}^{2}$ of roof has the general shape:

$$
G_{S a}=q_{C-A}+q_{C-H}+q_{\lambda},
$$

On the left side of equation (1), there is irradiance absorbed by the roof cover $G_{S a}$. The irradiance is part of total irradiance, $G_{S \beta}$, that reaches the surface of roofing. The remaining part of irradiance, $G_{S r}$, is reflected by the outer surface of the cover. On the right side of the equation (1), there are three heat fluxes, that is, the flux transferred between the roofing and the surrounding free air, $q_{C-A}$, the flux radiated from the outer layer of the cover to the sky (horizon), $q_{C-H}$, and the flux conducted by the construction of roofing and transferred into the interior of the building, $q_{\lambda}$. It is assumed for equation (1) that only transverse heat fluxes are analyzed. The roofing, as well as materials used for roof constructing are characterized with relatively low thickness which allows to neglect the heat transfer in the longitudinal direction. Particular energy fluxes can be determined from the given below equations:

$$
\begin{gathered}
G_{S a}=\left(1-r_{C}\right) G_{S \beta}, \\
q_{C-A}=h_{C-A}\left(T_{C}-T_{A}\right), \\
q_{C-H}=\varepsilon_{C} \sigma\left(T_{C}^{4}-T_{H}^{4}\right), \\
q_{\lambda}=U_{e}\left(T_{C}-T_{R}\right) .
\end{gathered}
$$

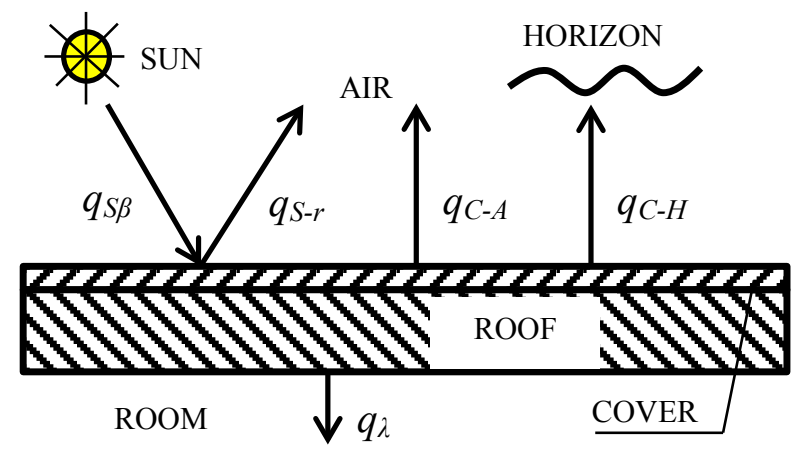

Fig. 1. Energy fluxes for roof $[17,18]$.

After substitution of relation $(2) \div(5)$ in equation (1), the following equation has been obtained:

$$
\begin{aligned}
& \left(1-r_{C}\right) G_{S \beta}=h_{C-A}\left(T_{C}-T_{A}\right)+ \\
& +\varepsilon_{C} \sigma\left(T_{C}^{4}-T_{H}^{4}\right)+U_{e}\left(T_{C}-T_{R}\right) .
\end{aligned}
$$

In equation (6), two parameters characterizing properties of roofing are present, that is, reflectivity $r_{C}$ and emissivity $\varepsilon_{C}$. Heat properties of roof are related by parameter $U_{e}$, called equivalent heat transfer coefficient. Its value depends on resistance of heat conduction by particular layers of roof $R_{i}$, and on resistance of heat transfer between the ceiling and the inside of interior $R_{R}$. Hence:

$$
U_{e}=1 / R_{e}=1 /\left(\sum_{i=1}^{N} R_{i}+R_{R}\right),
$$

Heat resistances can be calculated from the equations:

$$
\begin{aligned}
& R_{i}=\delta_{i} / \lambda_{i}, \\
& R_{R}=1 / h_{R} .
\end{aligned}
$$

Heat resistance of a flat layer of material depends on its thickness $\delta_{i}$ and on coefficient of heat conduction $\lambda_{i}$. Heat transfer between free air and roof cover depends on coefficient of heat transfer $h_{A-C}$, and heat transfer between the ceiling and the interior depends on coefficient $h_{R}$.

Thermodynamic stimulants for heat transfer are the temperature gradients. In heat balance equation (6) for roof, mean temperatures of particular media are applied. In order to calculate the sky temperature, the simplified Swinbank formula has been applied [19]:

$$
T_{H}=0.0553 \cdot T_{A}^{1,5} .
$$

Application of equation (6) for calculations of parameters that characterize optic properties of roof covers requires the knowledge of all the remaining parameters present in equations $(6)-(10)$. Besides, in equation (6) both reflectivity $r_{C}$, as well as emissivity $\varepsilon_{C}$ are unknown. So, value of one of the above parameters should be assumed, or an additional equation to define the relation between them should be written.

However, if energy balance for roof cover is valid only for the night time, equation (6) is simplified to the shape:

$$
\begin{gathered}
0=h_{C-A}\left(T_{C}-T_{A}\right)+\varepsilon_{C} \sigma\left(T_{C}^{4}-T_{H}^{4}\right)+ \\
+U_{e}\left(T_{C}-T_{R}\right) .
\end{gathered}
$$

Emissivity of roof cover can be determined from the above equation:

$$
\varepsilon=\frac{h_{C-A T_{A}+U_{e} T_{R}-\left(h_{C-A}+U_{e}\right) T_{C}}}{\sigma\left(T_{C}^{4}-T_{H}^{4}\right)} .
$$

\section{Experimental stand}

In order to determine temperatures of particular media, an experimental stand was built. The stand is presented in Fig. 2. Rectangular prism with dimensions: height $0.88 \mathrm{~m}$, length $-1.14 \mathrm{~m}$, and width $-0.84 \mathrm{~m}$ was a model of a building with a flat roof. The stand was placed on the roof of the building of Department of Heat Engineering, West Pomeranian University of Technology, Szczecin (Poland), on its south-west side. Walls of the stand were made of plywood with thickness of $0.014 \mathrm{~m}$ and insulated with rock wool with thickness of $0.005 \mathrm{~m}$ at the inner sides. Also plywood was used to 
build the roof. The roof was insulated with styrofoam with thickness of $0.1 \mathrm{~m}$. The outer surface of styrofoam was covered by the black roofing paper with unknown properties. The floor of the stand was insulated with a styrofoam plate with thickness of $0.1 \mathrm{~m}$.

In order to measure temperatures, five sensors of type Pt100 were used. They were connected with data recorder of type APAR206. The temperature sensors were placed:

- in the centre of roof cover surface (roofing paper),

- in the centre of styrofoam surface on the side of roofing,

- in the centre of styrofoam surface on the side of stand's interior,

- in the centre of inner space of the stand,

- behind the curtain, in order to measure the ambient temperature.

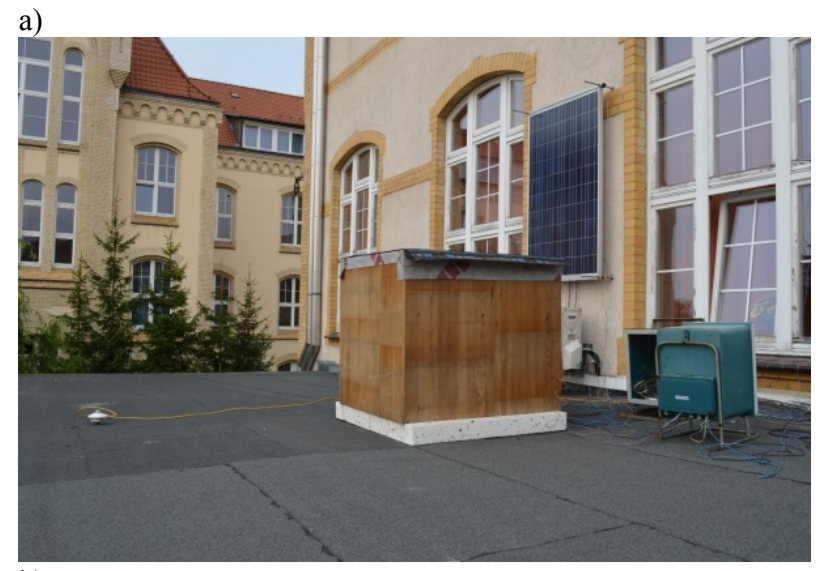

b)

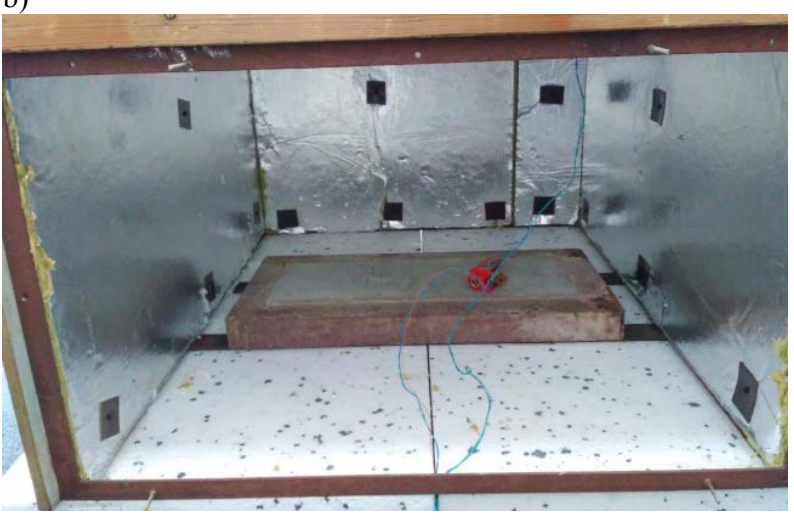

Fig. 2. Experimental stand: a) view b) interior (photo A.Walterowicz [20]).

Temperatures of particular layers of roof, of environment, and in of interior were measured every 3 minutes.

\section{Research results}

Experimental research was carried out in the time from 25.08.2017 to 14.09.2017. Initial analysis of obtained results is presented in paper [20]. Fig.3. shows characteristic temperatures distributions for media in particular night periods within the time under research.
Times of sunrise and sunset were determined on the basis of a computer program from the website [21]. It can be concluded from the analysis of measurements results that the lowest are temperatures of outer and inner surfaces of roofing paper. Air temperatures in the interior and at the inner surface of styrofoam have the highest values. Ambient temperatures have values higher than temperature of outer surface of roofing paper, but lower than values of air temperature in the interior. Thus, on the basis of Fig.3, it can be stated that heat is transferred from the outer air to the roof cover at night. The roof cover receives also the heat from the inner air. On the other hand, roof cover loses heat as a result of irradiance to the sky.

It was assumed for calculations that coefficient of heat transfer from the free air to the roof cover was known. Value of this coefficient was calculated with assumption that wind velocity was equal $1 \mathrm{~m} / \mathrm{s}$ [22]:

$$
h_{A-C}=2.8+3.0 w \text {. }
$$

The coefficient equals $h_{A-C}=5.8 \mathrm{~W} /\left(\mathrm{m}^{2} \mathrm{~K}\right)$. In turn, equivalent heat transfer coefficient equals $U_{e}=0.18$ $\mathrm{W} /\left(\mathrm{m}^{2} \mathrm{~K}\right)[17]$. The above value was calculated because heat resistance of styrofoam was known and the coefficient of heat transfer from styrofoam to inner air was assumed.

Fig.4 shows calculations results for emissivity for black roofing paper determined for the time of night. Values of emissivity change in a wide range. It may be caused by application of simplified Swinbank formula in order to calculate equivalent temperature of sky in the proposed methodology. Temperature of sky depends on content of water vapor in atmosphere and on cloudiness. It depends also on the time of the year and on the time of the day [23]. Choice of an adequate relation to calculate the temperature of sky, as Pluta [24] claims, is particularly relevant when the operation of solar installations in the night time is analyzed. Thus, if the sky is cloudy, temperature of sky calculated from simplified Swinbank formula (10) requires to be revised, or only cloudless (or nearly cloudless) nights in time under research can be analyzed.

Because of the above fact, analysis of irradiance distribution in the investigated time (Fig.5) was made. The end of August 2017 was the time in which it was stated that the sky was very little cloudy, as irradiance distribution was regular and time temperatures changes were mild. Thus, three August nights were chosen for further analysis, i.e. 25/26, 27/28, and 28/29 of August. Results of temperatures measurements and calculated values of roofing paper emissivity are shown in Figs 6 and 7. It results from analysis of temperatures distributions for chosen nights that the mildest changes occurred at night 25/26 of August 2017. Roofing paper emissivity calculated from equation (12) shows tendency to oscillate around the mean value of this parameter equal 0.63 . So, it can be assumed that the black roofing paper under research is characterized by emissivity close to this value. 


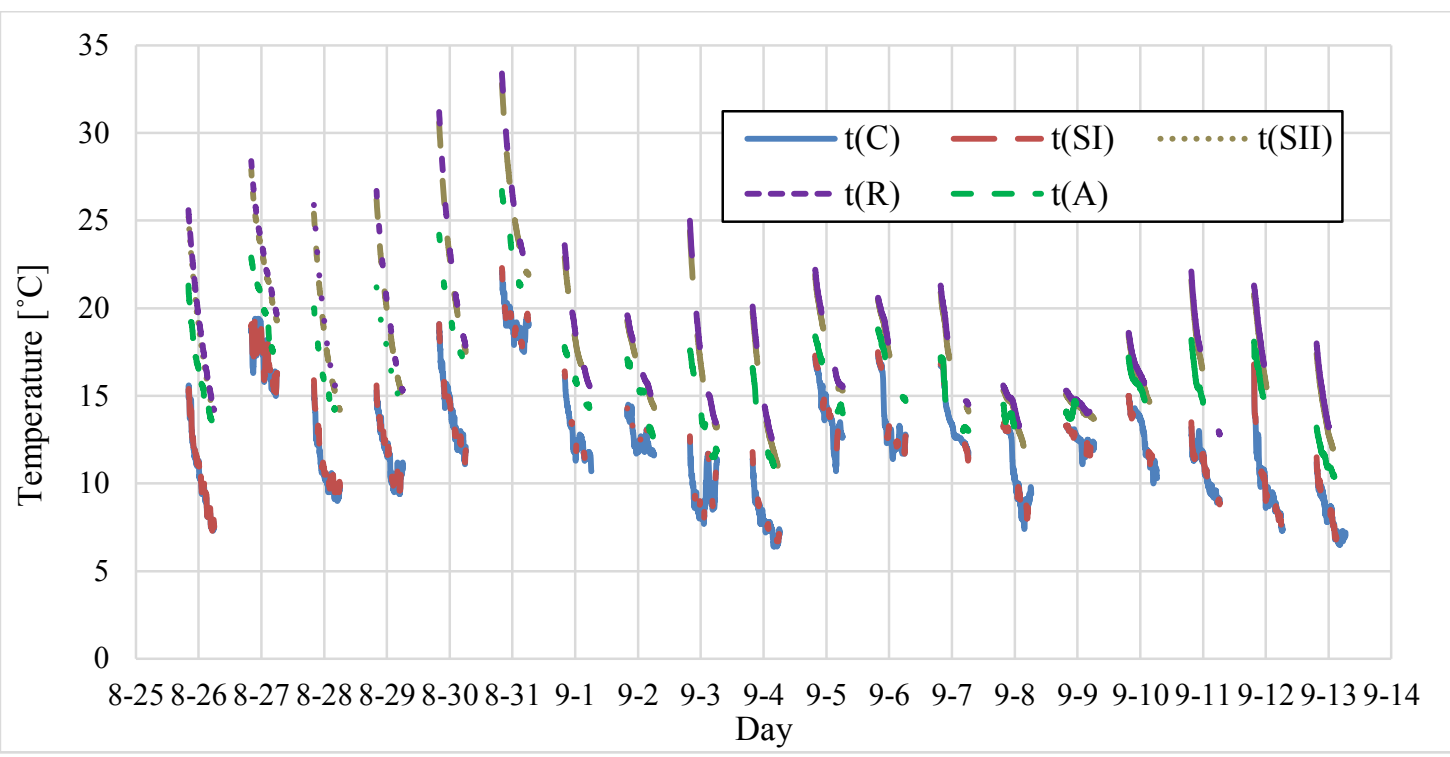

Fig. 3. Temperatures distributions in particular nights measured in the time from 25.08.2017 to 13.09.2017.

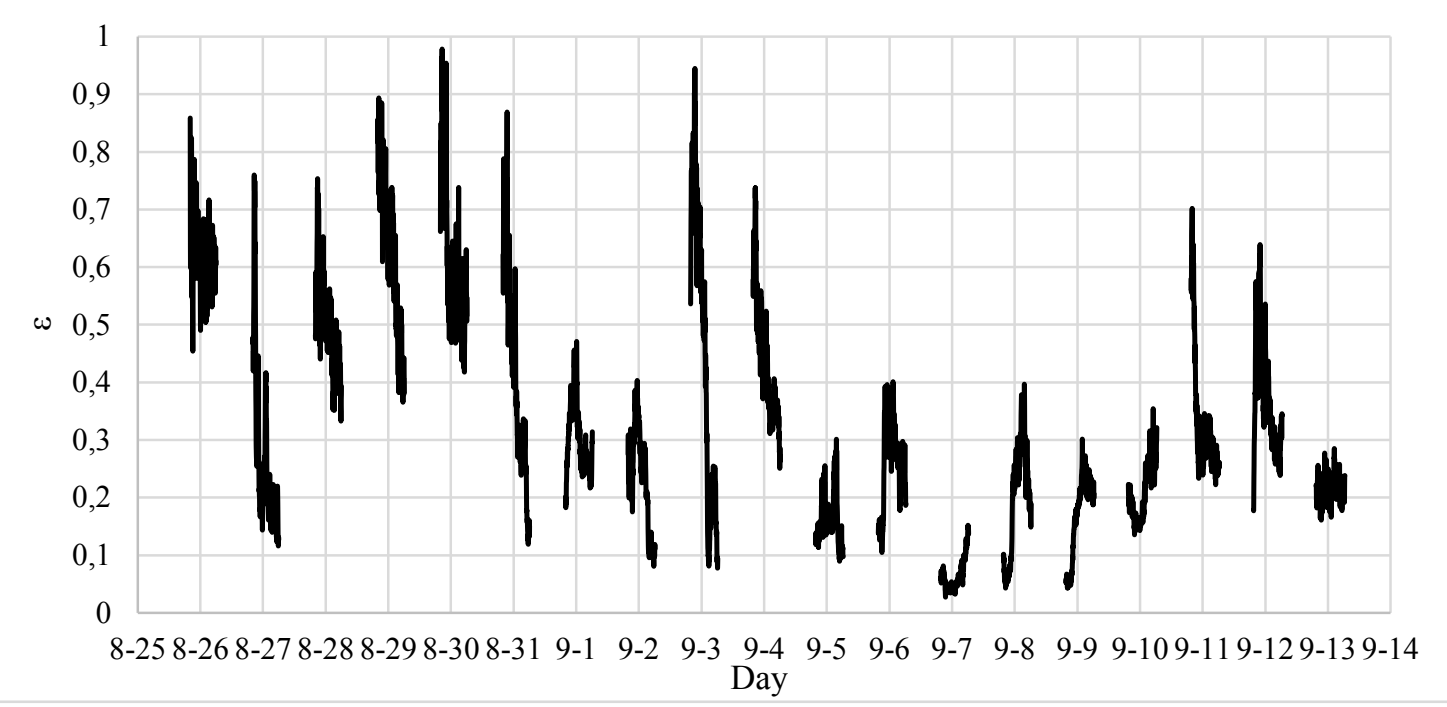

Fig. 4. Emissivity calculated for the night time in the period from 25.08.2017 to 13.09.2017.

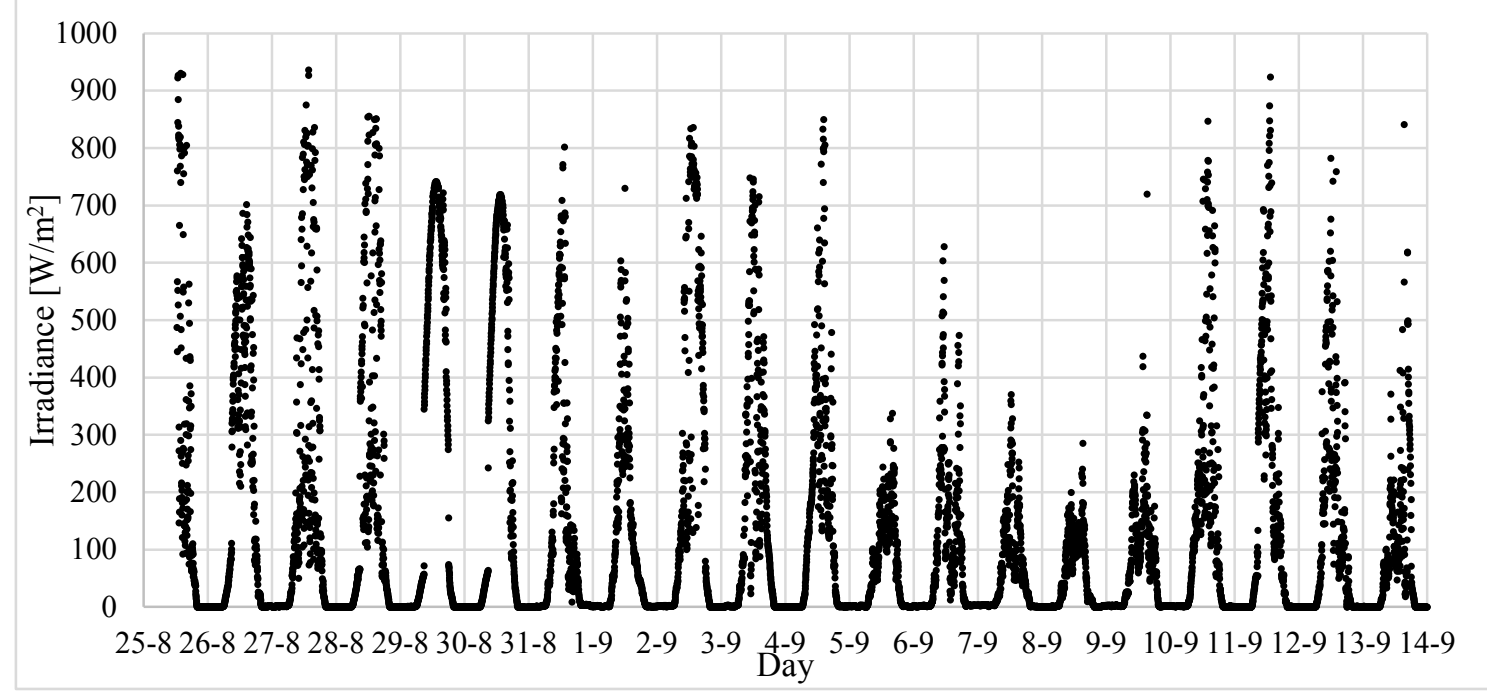

Fig. 5. Irradiance in the period from 25.08.2017 to 14.09.2017. 
However, the proposed methodology of determination the emissivity requires further modifications in order to a.o. more explicitly determine the value of temperature of sky.

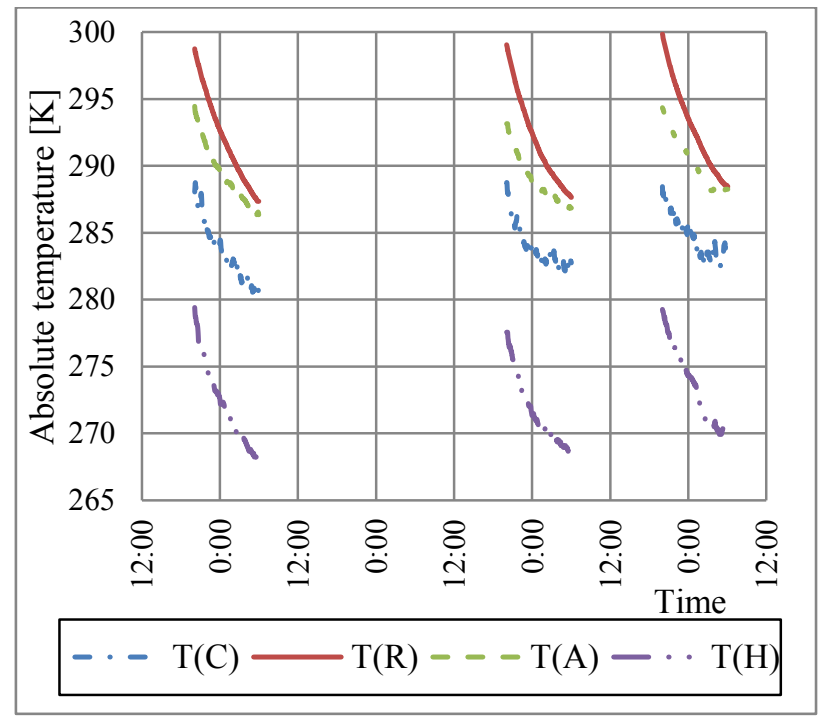

Fig.6. Characteristic absolute temperatures of media; nights 25/26, 27/28, and 28/29 of August 2017.

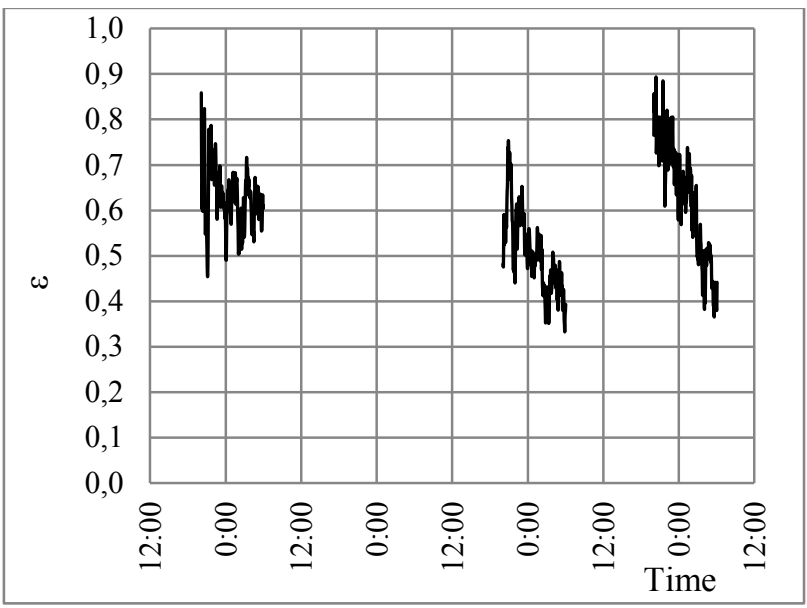

Fig. 7. Emissivity for roofing paper under research; nights 25/26, 27/28, and 28/29 of August 2017.

\section{Conclusions}

On the basis of carried out analysis of research results, the following conclusions can be proposed:

a) the methodology of research proposed in the paper allows to estimate the value of emissivity for roof cover,

b) the methodology requires experimental research to be carried out where determination of mean temperatures of particular media are needed; temperatures for a cloudless and nearly windless night should be chosen for calculations,

c) equation describing the temperature of sky should be modified or replaced by another one in order to increase accuracy of proposed methodology,

d) for the black roofing paper under research, the emissivity equals ca 0.63 .

\section{References}

1. Directive 2012/27/EU of the European Parliament and of the Council of 25 October 2012 on energy efficiency, amending Directives 2009/125/EC and 2010/30/EU and repealing Directives 2004/8/EC and 2006/32/EC, Official Journal of the European Union, L 315/1, (2012)

2. L. Pérez-Lombard, J. Ortiz, Ch. Pout, Energ. Buildings, 40, 394-398 (2008)

3. H. Zhao, F. Magoulès, Renewable and Sustainable Energy Reviews, 16, 6, 3586-3592 (2012)

4. N. Fumo, Ren.Sust. Energ. Rev., 31, 53-60 (2014)

5. P. Kivimaa, M. Martiskainen, Energ. Effic., 11, 1, 31-51 (2018)

6. Y. Anand, A. Gupta, A. Maini, Avi Gupta, A. Sharma, A. Khajuria, S. Gupta, S. Sharma, S. Anand, S.K. Tyagi, J. Eng., Article ID 685640, 9 pages (2014)

7. E. Di Giuseppea, M. Pergolinib, F. Stazib, Energ. Procedia, 134, 404-413, (2017)

8. O. Sandin, J. Nordin, M. Jonsson, J. Coat. Technol. Res., 14, 4, 817-821 (2017)

9. https://energy.gov/energysaver/energy-efficienthome-design/cool-roofs

10. https://heatisland.lbl.gov/coolscience/cool-roofs

11. https://www.epa.gov/heat-islands/using-cool-roofsreduce-heat-islands

12. J. Šabíková, L. Krčmárová, J. Sustain. Construct. Mater. Technol., 1, 2, 60-63 (2016)

13. H. Suehrckea, E.L. Petersonb, N. Selbyd, Energ. Buildings, 40, 2224-2235 (2008)

14. R. Levinson, H. Akbari, Energ. Effic., 3, 1, 53-109 (2010)

15. A.L. Piselloa, F. Cotanaa, L. Brinchia, Energ. Procedia, 45, 453-462 ( 2014)

16. http://coolroofs.org

17. Z. Zapałowicz, J. Mech. Energ. Eng., 41, 1, 107-112 (2017)

18. Z. Zapałowicz, 24 Symp. Nutzung Regenerative Energiequellen und Wasserstofftechnik, 9. 11.11.2017 Stralsund, Germany, 167-176 (2017)

19. J.A. Duffie, W.A. Beckman, Solar Energy Thermal Processes. John Wiley \& Sons, New York, (1991)

20. A. Walterowicz, Lic. Work, West Pomeranian University of Technology, Szczecin (2018), (in Polish)

21. http://darekk.com/sun/sunrise-sunsetcalculator? lat $=53.42444444 \&$ lon $=14.56027778 \& z=$ $10 \& \mathrm{tz}=+1 \&$ loc $=$ Szczecin

22. J. Cieśliński, J. Mikielewicz. Nonconventional Sources of Energy. Wyd. Politechniki Gdańskiej, Gdańsk p.59, (1996), (in Polish)

23. H. Nowak, Infrared Physics, 29 (2-4), 231-232 (1989)

24. Z. Pluta, Podstawy teoretyczne fototermicznej konwersji energii stonecznej. Oficyna Wyd. Politechniki Warszawskiej, Warszawa (2000) (in Polish) 